\title{
Demand-Response Based Energy Advisor for Household Energy Management
}

\author{
Fayiz Alfaverh \\ University of Hertfordshire \\ Fayiz91_alfawareh@hotmail.com
}

\author{
Mouloud Denaï \\ University of Hertfordshire \\ m.denai@herts.ac.uk
}

\author{
Khaldoon Alfaverh \\ Budapest University \\ Khaldoon26@icloud.com
}

\begin{abstract}
Home energy management systems (HEMS) are set to play a key role in the future smart grid (SG). HEMS concept enables residential customers to actively participate in demand response programs (DR) to control their energy usage, reduce peak demand and therefore contribute to improve the performance and reliability of the grid. The aim of this paper is to propose an energy management strategy for residential endconsumers. In this framework, a demand response strategy is developed to reduce home energy consumption. The proposed algorithm seeks to minimise peak demand by scheduling household appliances operation and shifting controllable loads during peak hours, when electricity prices are high, to off-peak periods, when electricity prices are lower without affecting the customer's preferences. The overall system is simulated using MATLAB/Simulink and the results demonstrate the effectiveness of the proposed control strategy in managing the daily household energy consumption.
\end{abstract}

Keywords - demand response, smart home, home energy management system, renewable energy, energy storage.

\section{INTRODUCTION}

Greenhouse gas emissions are posing a serious concern around the world due to their impact on the environment and climate change. The global economy, on the other hand, is in the midst of unprecedented demand for energy requiring new investments for the reinforcement and expansion of grid infrastructures and the large adoption of renewable energy resources. Consequently, energy prices are set to gradually increase. Demand Response (DR) is considered as an important element that can help customers control their energy usage [1]. Engaging consumers in DR will reduce power consumption during peak demand hours and provides savings in electricity bills [2]. DR can be defined as a change in electricity consumption pattern of end-users by increasing or decreasing the loads in response to tariff signals and other incentives from the energy supplier [3], [4]. However, residential consumers do not want to spend time on calculating and analysing their power consumption and scheduling their household devices to save money [1]. Therefore, the grid communication infrastructure and smart appliances must to be able to respond to any electricity consumption scenario envisaged by consumers. Home Energy Management System (HEMS) is a demand response tool that improves the energy utilisation and seeks to reduce electricity cost by shifting and curtailing demand in response to electricity tariffs and consumer comfort during peak hours [1], [2], [4], [5]. Many researchers are working towards developing efficient and reliable HEMS that can be categorised into predictive energy management and real-time management. In recent literatures [6], [7], forecasting is used along with energy management systems to predict consumption and supply availability to achieve demand/supply balance and improve the stability of the grid. However, forecasting algorithms are very complex and not accurate, which makes this approach difficult to implement [8]. Therefore, forecasting algorithms with maximum accuracy and minimum computational effort is still an open area of research. Other studies have focused on the development of real-time algorithms [9], [10], [11] to control thermal appliances or shift the operation time of a controllable devices. These algorithms aim mainly at reducing peak demand and electricity bills [9]. Some other researchers, on the other hand, used these real-time techniques to optimise power consumption [12]. In this research, the proposed control strategy is based on a demand response algorithm and aims to smooth the power consumption profile without sacrificing customer comfort and preferences.

\section{SMART Home ENERGY MANAGEMENT Systems}

A smart HEMS is an essential home system to achieve the successful demand-side response (DSR) and DR in SG. It is used to monitor and control various home appliances in real time, based on the customer's preferences via the smart home humanmachine interface (HMI). Consequently, this helps reduce electricity cost and achieve efficient energy utilisation efficiency. According to DR programs, smart HEMS provides an opportunity for economic incentives of smart home in order to manage demand-side loads by shifting electricity consumption during peak demand in response to changes in electricity price. Therefore, smart HEMS is defined as "a system that is used to provide different energy management services such as monitoring, controlling and managing energy generation, energy storage, and energy consumption in smart houses" [5]. Using communication and sensor technologies in home area networks (HAN), energy usage from all household appliances, can be continuously monitored. Different operation modes of home appliances can then be implemented remotely using a personal computer of s smart phone. In order to achieve electricity saving and DR, HEMS should be more flexible to control and manage household appliances, renewable energy sources (RES) and home energy storage system (HESS). Furthermore, real time kWh and energy pricing in smart home can be provided to consumers. Based on that, users can choose their preferences via the HMI to schedule the operation time of various appliances to improve their energy usage efficiency. Fig. 
1 illustrates the five main functions of smart HEMS, including monitoring, logging, control, management and alarm.

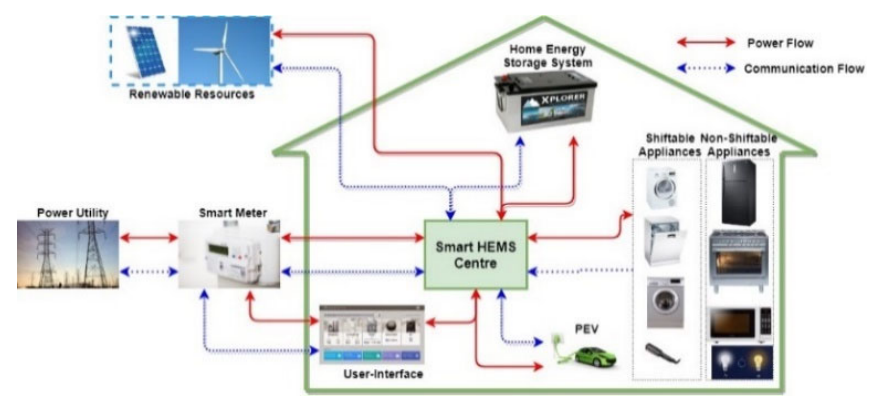

Fig. 1. Smart HEMS architecture

\section{1) Monitoring}

This functionality offers consumers easy access to their energy consumption in real-time in order to make them more aware about the electricity saving. It also provides services for the operational modes and energy status of each home appliance.

\section{2) Control}

The control functionality is classified into two types based on the ability to have access to household appliances. Namely, direct control and remote control. Direct control is applied on both the appliances and control system. Whereas remote control enables consumers to monitor and control their appliances online via a personal computer or smart phone from outside the home.

\section{3) Management}

The most important function of HEMS is energy management services in order to optimise the power consumption in the smart home. This functionality includes renewable energy system management, energy storage management, home appliance management.

\section{4) Logging}

HEMS aims also to collect and save data on power consumption of appliances, generation from renewable energy resources, and the energy storage state of charge. It also receives real-time prices from power utility and contains demand response analysis.

\section{Proposed Demand Response Strategy}

HEMS are considered as an integral part of a smart grid that play a crucial role in achieving DR applications for residential customers, which aim to minimise electricity bills and maximise energy efficiency. HEMS provide economic incentives for customers to manage demand-side appliances by shifting electricity consumption during peak demand in response to changes in electricity price, as the majority of customers do not have time to manage, control and monitor their electricity consumption. In this study, a DR algorithm is proposed for household energy management making HEMS more effective and enabling customers to actively participate in the DR program without actually compromising their lifestyle. According to the daily power consumption profile shown in Fig. 2 , there are two main critical periods or peak demand periods that occur usually during morning and evening times where the electricity price is high.

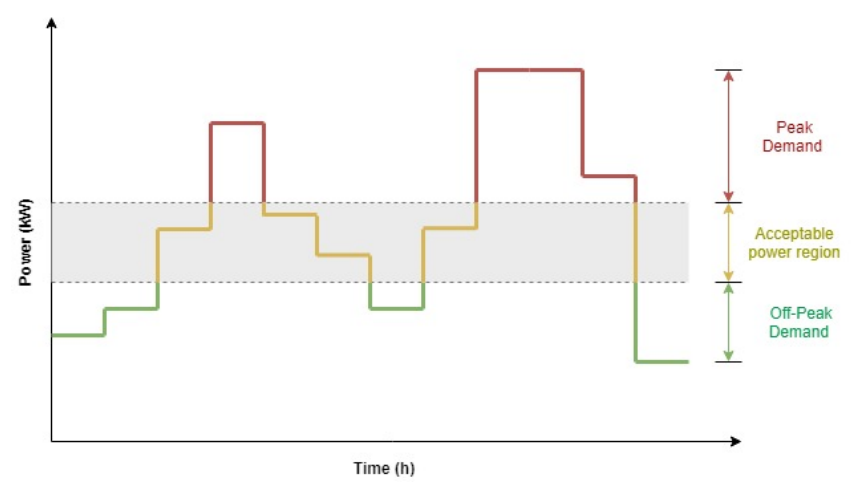

Fig. 2. Daily household power consumption

There is also off-peak demand which corresponds to a low electricity price due to a decrease of consumer's activities such as cooking, washing, cleaning and watching TV. Therefore, this proposed algorithm aims to avoid power consumption during these peak period and allowing power consumption within the acceptable power region, which is a normal level for consuming power, as much as possible. This can be achieved by shifting the operating time of specific appliances from peak demand to off peak without compromising the user's preferences. For this reason, the household appliances are divided mainly into two categories; shiftable appliances that have the ability to reschedule their operating time based on load priority and preference setting such as washing machine, dish washer and electric vehicle. Non-shiftable appliances require a permanent power supply during operating time regardless of the electricity price. Table 1 and 2 show the rated power of both categories.

TABLE 1 RATED POWER For NON-ShifTABle APPLIANCES

\begin{tabular}{|c|c|}
\hline Appliance & Rated Power (W) \\
\hline Iron & 1000 \\
\hline Oven & 2000 \\
\hline Laptop & 20 \\
\hline Microwave & 600 \\
\hline Television & 200 \\
\hline Lighting & 100 \\
\hline Refrigerator & 200 \\
\hline Water heater & 2000 \\
\hline
\end{tabular}

TABle 2 Rated Power For Shifatble ApPliances With Priority

\begin{tabular}{|c|c|c|}
\hline Appliance & Rated Power (W) & Priority order \\
\hline Washing machine & 800 & 1 \\
\hline Dish washer & 1100 & 2 \\
\hline Clothes dryer & 400 & 4 \\
\hline Hair dryer & 450 & 5 \\
\hline Hair straightener & 20 & 6 \\
\hline PEV & 1200 & \\
\hline
\end{tabular}


The proposed HEM system works based on real-time pricing (RTP), which is considered as a dynamic pricing. Using this DR program, the customers are informed about the prices on dayahead or hour-ahead basis as the electricity price varies at different time intervals of a day. Therefore, smart meters are used to receive the RTP signal from a utility and record the current power consumption data of all household appliances during operating times, and then send them to the HEM system. In addition, this proposed algorithm works based on load priority and customer comfort preference. A user-interface is used to enable customers to set the priority of shiftable appliances. Consequently, the HEM system can shift the operating time of appliance that has the lowest priority during peak demand when required, and then turn on the appliance that has the highest priority during off-peak hours. Based on the relationship of the real-time price, the consumed power by all household appliances taking into account load priority and customer comfort preference (i.e. accepted price and consuming power region), the proposed algorithm provides three operating modes as shown in Fig. 3.

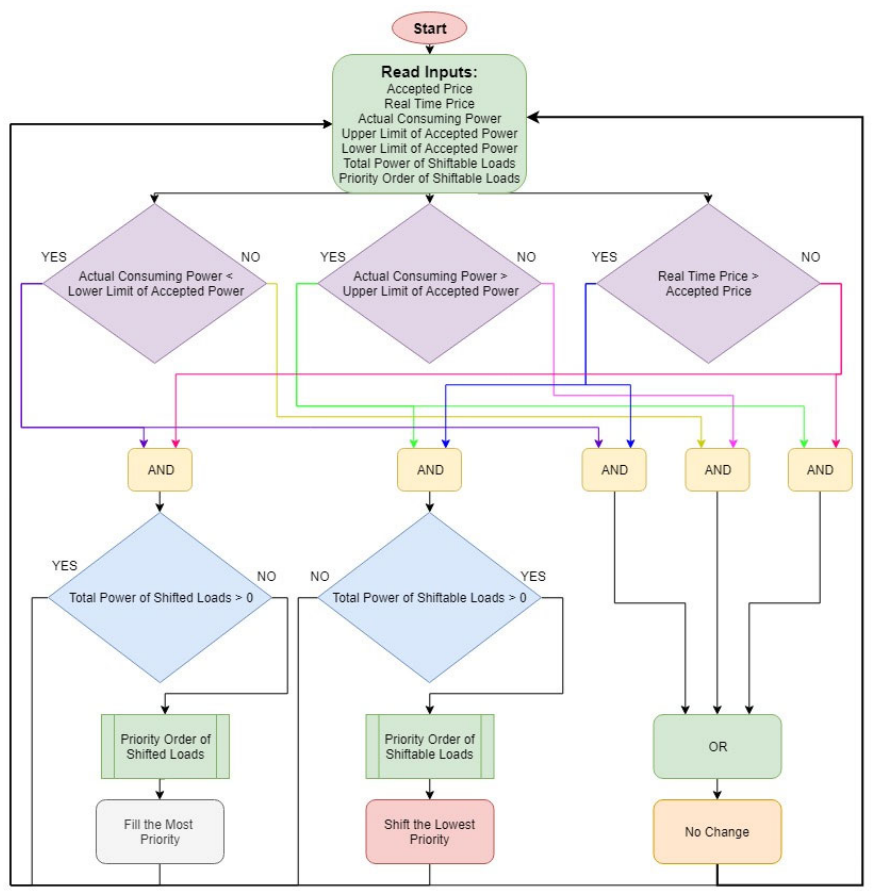

Fig. 3. Flowchart of the proposed demand response strategy

1) Mode 1 : Do Nothing, this occurs when:

a) Mode 1.1: The real-time price is lower than the accepted price and the total power consumption is more than the upper limit of the accepted consumed power.

b) Mode 1.2: The real-time price is higher than the accepted price and the total power consumption is less than the lower limit of the accepted consumed power.

c) Mode 1.3: The total power utilisation is within the acceptable consuming power region.
2) Mode 2: Shifting, that shifts the minimum priority device. This mode occurs always during peak demand; the real price is high (more than accepted price) and the consumed power is also high (more than the maximum level of the accepted power utilisation region).

3) Mode 3: Valley Filling that turns on the shifted appliance with the highest priority during off-peak demand hours.

This study aims also to provide a useful simulation platform for HEMS algorithms in order to enable researchers and developers to implement and test their proposed control algorithms. The proposed HEM model includes mainly solar panel, power electronic devices, household appliances, energy storage system and user-interface as shown in Fig. 4.

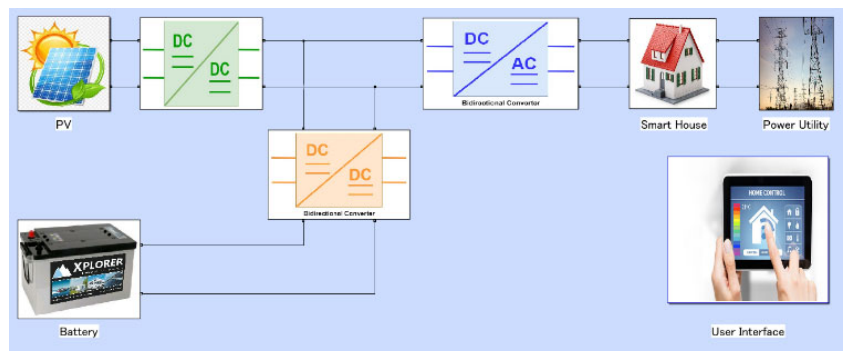

Fig. 4. HEMS model developed in MATLAB

The designed user-interface enables the user to control and manage the energy utilisation and input his preference settings. In addition, it allows the user to monitor the cost of consumed energy for each appliance individually and the total cost of power consumption by all devices. The proposed user-interface provides auto and manual operating for every device as shown in Figs. 5 and 6. In auto mode, the system will shift the operating time of appliance when required without permission from the user and provide a shifted signal by lighting the green LED. When the system detects Mode 3 during off-peak demand, the shifted appliance will be turned on. However, the user can switch on the manual button in order to control the device manually if she/he does not want to operate that appliance with auto mode. In other words, the appliance can operate regardless of which mode the system is working with. This enables the user to make more effective decisions and therefore makes the management process more flexible.

\section{RESUlTS AND DisCUSSION}

From Fig. 7, the electricity price is below the acceptable price during the off-peak hours and more than the accepted price during peak demand.

Fig. 8 shows the daily power consumption. It is clear that the consumed power is more than the upper limit of the acceptable power region during morning and evening times. Whereas it is less than the lower limit of acceptable region during other times of that day (off-peak). 


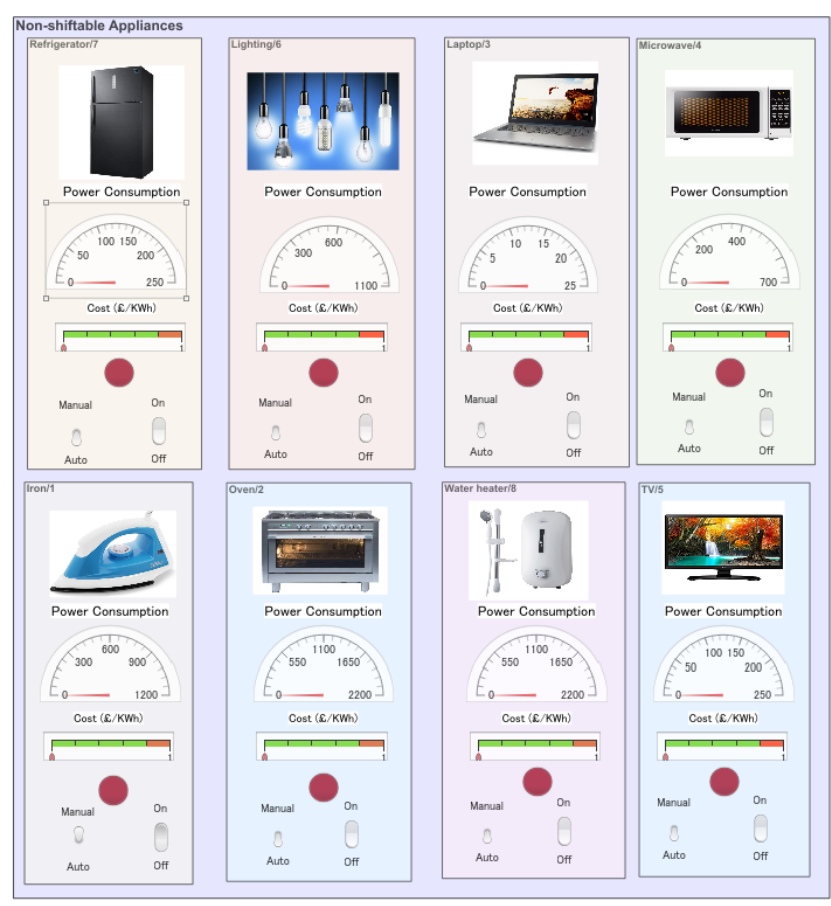

Fig. 5. Non-shiftable appliances window in the user-interface

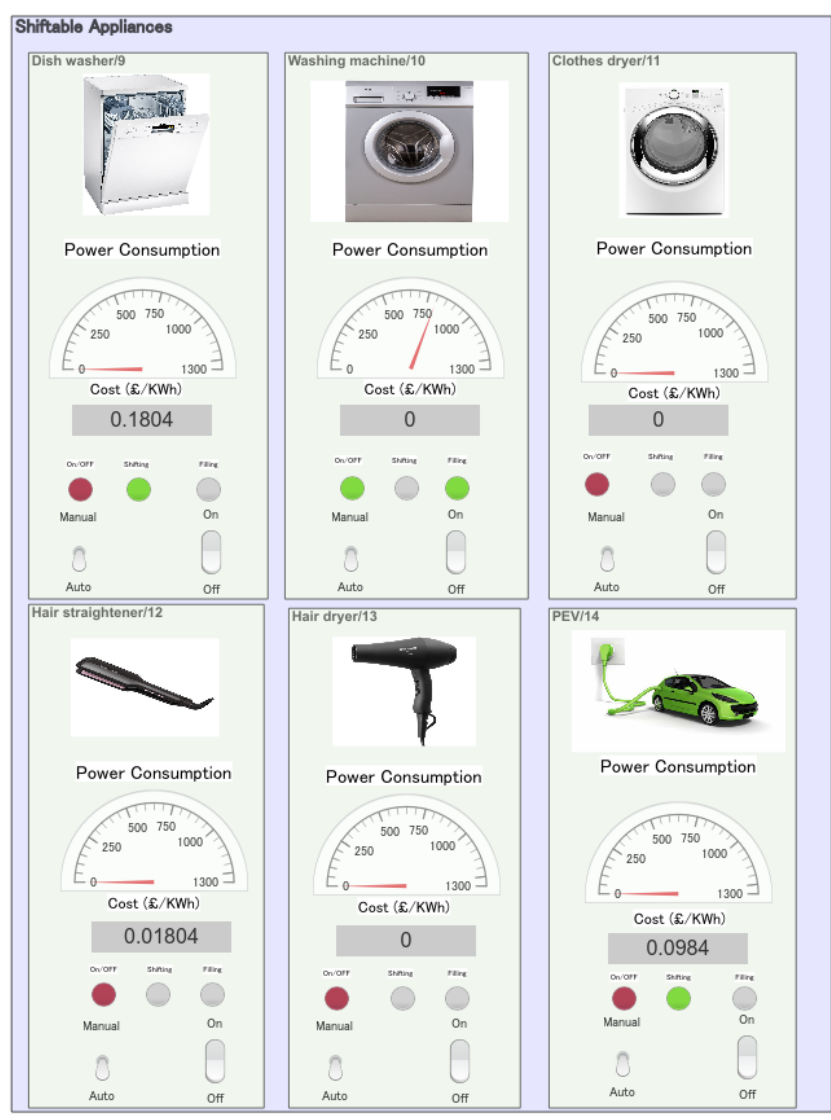

Fig. 6. Shifatble appliances window in the user-interface

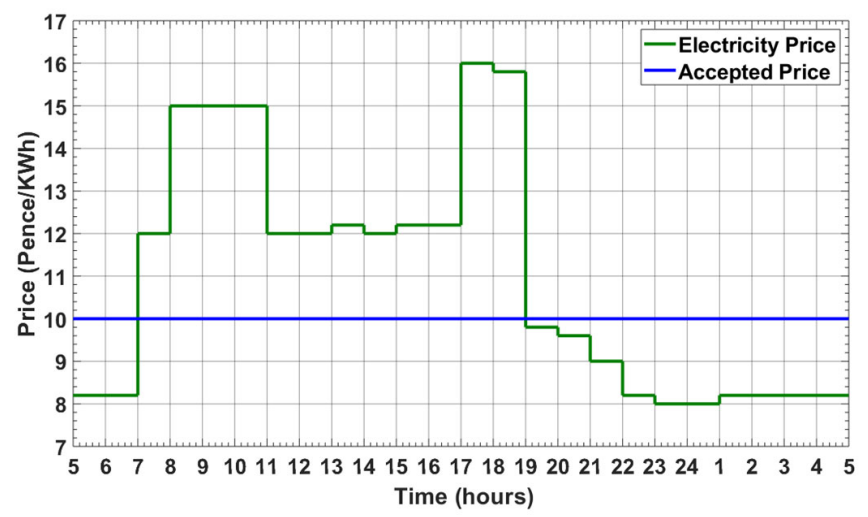

Fig. 7. Real time price and average price signals

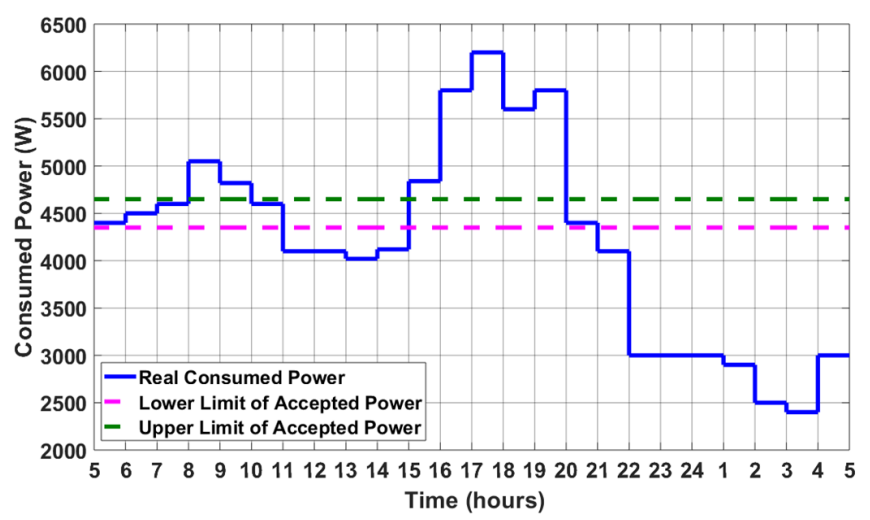

Fig. 8. Power consumption by the smart home's appliances

Based on the electricity price and current power consumption shown in Figs. 7 and 8, the proposed DR strategy detects the three operating modes as shown in Fig. 9.
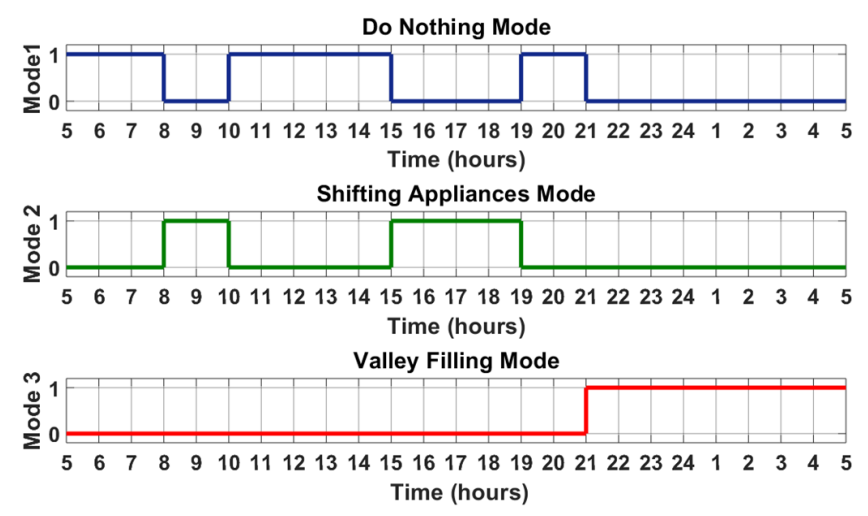

Fig. 9. Different operating modes

[5:00 am - 8:00 am]: During this time the proposed control algorithm detects Mode 1 . Since the actual price is less than the accepted price, and the power demand is in the acceptable power range. As a result of this, the system will advise the user to maintain the operating state as it is.

[8:00 am - 10:00 am]: Mode 2 is detected in this interval as the peak load demand. During these two hours the required power is more than the upper limit of the acceptable power and 
the price is higher than the acceptable price. During this time, the user will be advised to re-schedule their shiftable appliances.

[10:00 am - 3:00 pm]: Mode 1 is detected again during this time. Because the load demand is below the lower limit of the power acceptable while the price is more than the acceptable price.

[3:00 pm - 7:00 pm]: This is the time of peak loads demand (Mode 2), where power demand is more than the upper limit of the acceptable power and the price is more than the average price. Therefore, the shiftable appliances should be shifted to off-peak hours.

[7:00 pm - 9:00 pm]: In these two hours, the system detects Mode 1 due to two different reasons. During the first hour, the price is less than the average but the required power is more than the upper limit acceptable power. In the second hour, the demand is in the acceptable power range.

[9:00 pm - 5:00 am]: During this time the system advises the user to switch on the shiftable appliances which have been shifted. This Mode 3 is detected because the price is less than the average price and the power required is less than the lower limit of the acceptable power range.

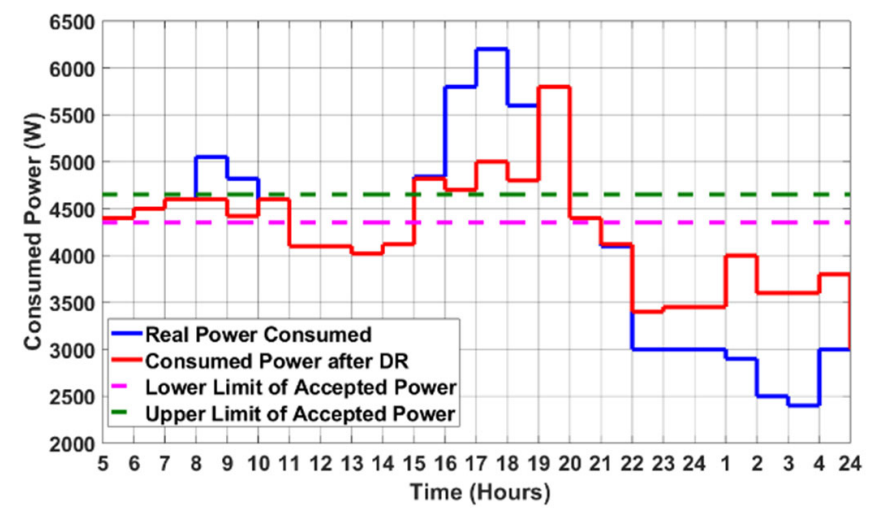

Fig. 10. Power consumption profile with the implementation of the demand response strategy

\section{CONCLUSION}

The main contribution of this work is to develop a demand response algorithm, which is aimed to minimise energy usage and electricity bills by shifting load demand, in response to electricity prices and consumer preferences, during peak hours when the electricity price is high, to off-peak demand when the electricity price is low. In this study, an optimal household energy management is proposed. The proposed HEMS model has been implemented using MATLAB and SimPowerSystems toolbox and a graphical user interface has been designed to implement and test demand response and control algorithms.

\section{REFERENCES}

[1] Shakeri, M., Shayestegan, M., Abunima, H., Reza, S. S., Akhtaruzzaman, M., Alamoud, A., ... \& Amin, N. (2017). An intelligent system architecture in home energy management systems (HEMS) for efficient demand response in smart grid. Energy and Buildings, 138, 154-164.

[2] Aalami, H. A., Moghaddam, M. P., \& Yousefi, G. R. (2010). Modeling and prioritizing demand response programs in power markets. Electric Power Systems Research, 80(4), 426-435.

[3] Beaudin, M., \& Zareipour, H. (2017). Home Energy Management Systems: A Review of Modelling and Complexity. In Energy Solutions to Combat Global Warming(pp. 753-793). Springer, Cham.

[4] Stoll, P., Brandt, N., \& Nordström, L. (2014). Including dynamic CO2 intensity with demand response. Energy Policy, 65, 490-500.

[5] Zhou, B., Li, W., Chan, K. W., Cao, Y., Kuang, Y., Liu, X., \& Wang, X. (2016). Smart home energy management systems: Concept, configurations, and scheduling strategies. Renewable and Sustainable Energy Reviews, 61, 30-40.

[6] Kong, W., Dong, Z. Y., Hill, D. J., Luo, F., \& Xu, Y. (2018). Short-term residential load forecasting based on resident behaviour learning. IEEE Transactions on Power Systems, 33(1), 1087-1088.

[7] Khan, A. R., Mahmood, A., Safdar, A., Khan, Z. A., \& Khan, N. A. (2016). Load forecasting, dynamic pricing and DSM in smart grid: A review. Renewable and Sustainable Energy Reviews, 54, 1311-1322.

[8] Abedinia, O., Amjady, N., \& Zareipour, H. (2017). A new feature selection technique for load and price forecast of electrical power systems. IEEE Transactions on Power Systems, 32(1), 62-74.

[9] Anvari-Moghaddam, A., Monsef, H., \& Rahimi-Kian, A. (2015). Optimal smart home energy management considering energy saving and a comfortable lifestyle. IEEE Transactions on Smart Grid, 6(1), 324-332.

[10] Hossain, M. A., Pota, H. R., Squartini, S., \& Abdou, A. F. (2019). Modified PSO algorithm for real-time energy management in gridconnected microgrids. Renewable Energy, 136, 746-757.

[11] Rasheed, M., Javaid, N., Awais, M., Khan, Z., Qasim, U., Alrajeh, N., ... \& Javaid, Q. (2016). Real time information based energy management using customer preferences and dynamic pricing in smart homes. Energies, 9(7), 542.

[12] Conejo, A. J., Morales, J. M., \& Baringo, L. (2010). Real-time demand response model. IEEE Transactions on Smart Grid, 1(3), 236-242. 